\title{
Acute oral toxicity and anti-inflammatory activity of hydroalcoholic extract from Lampaya medicinalis Phil in rats
}

\author{
Glauco Morales ${ }^{1,2^{*}}$, Adrián Paredes $^{2}$, Alberto Olivares ${ }^{3}$ and Jaime Bravo ${ }^{4}$
}

\begin{abstract}
Background: Algesia and inflammation are related with several pathological conditions. It is known that many drugs available for the treatment of these problems cause unwanted side effects. This study was aimed at evaluating acute toxicity and anti-inflammatory activity of Lampaya medicinalis Phil. (Verbenaceae) widely used in the folk medicine of Northern Chile against rheumatism, arthritis and body joints pain.

Results: Oral administration of hydroalcoholic extract (HAE) at the highest dose of $3000 \mathrm{mg} / \mathrm{Kg}$ body weight resulted in no mortalities or evidence of significant behavioral changes. Histological examination revealed normal architecture and no significant adverse effects were observed on the liver, kidney, heart, lung or ovaries and testicles. The results suggest that the oral administration of hydroalcoholic extract (HAE) from Lampaya medicinalis did not produce any toxic effect in rats. Hydroalcoholic extract (HAE) significantly inhibited the carrageenan-induced rat paw edema in dose - response relationship, at test doses of 37.5, 75, 150 and $300 \mathrm{mg} / \mathrm{Kg}$ body weight. Maximum inhibition (61.98 $\pm 2.69 \%$ ) was noted at $300 \mathrm{mg} / \mathrm{Kg}$ after $2 \mathrm{~h}$ of drug treatment carrageenan induced paw edema, whereas indomethacin produced $47.90 \pm$ $1.16 \%$ of inhibition. The inhibitory values of edema at $3 \mathrm{~h}$ postcarrageenan were $31.04 \pm 0.75 \%, 40.51 \pm 2.36 \%, 48.97 \pm$ $1.14 \%$ and $56.87 \pm 0.41 \%$ for $37.5,75,150$, and $300 \mathrm{mg} / \mathrm{kg}$ of extract respectively. Indomethacin $(10 \mathrm{mg} / \mathrm{Kg})$ gave a percentage inhibition of $49.44 \pm 1.44$. HAE (300 and $150 \mathrm{mg} / \mathrm{kg}$ ) induced an anti-inflammatory effect greater than (or comparable) with the effect of indomethacin from 2nd to 4 th hours of the experiment.
\end{abstract}

Conclusions: Our results reveal for first time that compounds contained in the hydroalcoholic extract of Lampaya medicinalis Phil exert anti-inflammatory effect and the oral administration is safe and non toxic up to dose level $3000 \mathrm{mg} / \mathrm{kg}$ body weight. The anti-inflammatory activity may be associated with the presence of flavonoids. These findings also justify the traditional use of the plant for treating pain.

Keywords: Lampaya medicinalis, Hydroalcoholic extract, Acute oral toxicity, Histology, Hematology, Anti-inflammatory, Carrageenan

\section{Background}

Medicinal plants are popular remedies used by a majority of the world's population. The efficacy of medicinal plant in the management of diseases is indubitable. The World Health Organization estimated that $80 \%$ of the population of developing countries, continues to use traditional medicine in primary medical problems. Several plants are typically

\footnotetext{
*Correspondence: gmorales@uantof.cl

'Departamento de Química. Facultad de Ciencias Básicas, Universidad de Antofagasta, Antofagasta, Chile

${ }^{2}$ Laboratorio de Química Biológica, Instituto Antofagasta (IA), Universidad de Antofagasta, Antofagasta, Chile

Full list of author information is available at the end of the article
}

used without considering the toxicity and pharmacological aspects. The toxicity herbal preparation is usually unknown and the population does not care, believing that if the material has being used so far, it should be devoid of toxicity [1].

Information on the toxicity of the plants is very important as baseline before further exploring its development as a new herbal medicine [2].

Standard experimental methods are useful for the validation of ethnopharmacological knowledge regarding herbal medicine. Many studies are carried out to validate the use of medicinal plants in an effective and safe way $[3,4]$.

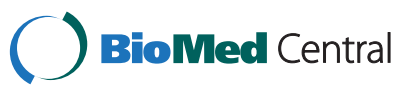


Acute toxicity studies are commonly used to determine signs of toxicity and effects on biochemical, hematological and histological parameters.

Chronic inflammation diseases remain one of the world's major health problems. Inflammation has become the focus of global scientific research because of its implication in virtually all human diseases [5]. Since conventional anti-inflammatory drugs have not been successful in some inflammatory processes, there is an urgent need to have new and safe anti-inflammatory agents [6]. Attention is being focused on the investigation of the efficacy of plants-based drugs used in the traditional medicine [6]. Inhibition of carrageenan-induced inflammation has been shown to be highly predictive of anti-inflammatory drug activity.

Andean High Plateau in Northern Chile, known as "Puna atacameña", is a particular biotope characterized by varying altitudes of between 3000-4200 meters above sea level, a very low relative humidity, no rains, cloudless skies during most of the year. Around 5000 peoples live in this peculiar ecological system and they use medicinal plants as curatives or palliatives of health problems because the plants are recognized as a traditional way to treat ailments and diseases.

Lampaya medicinalis Phil (Verbenaceae) commonly known as "lampaya", is a small bush, with a height of $80-100 \mathrm{~cm}$ that grows in the "Puna atacameña" in Northern Chile.

There is little or no information about the chemical composition or medicinal properties of this plant in the scientific literature; however, oral reports from herbal medical practitioners indicate that the infusion of the plant is usually prepared and given for treatment of colds, stomach pain, urinary bladder discomforts, as antitussive, and against rheumatism, arthritis and body joints pain [7-10]. It has been reported that agents isolated from Lampaya hieronymi exhibit anti-inflammatory activity [11].

The objective of this research was to validate the use of Lampaya medicinalis for folklore medicine, therefore anti-inflammatory potential of the hydroalcoholic extract from on carrageenan-induced rat paw edema was explored, toxicity was evaluated using an acute oral toxicity test in rats under the Organization for Economy Cooperation Development guidelines $[12,13]$ and the phytochemical screening of hydroalcoholic extract was evaluated [14].

\section{Results}

\section{Acute toxicity study}

\section{Lethality and behavioral analysis}

In this 14-days period of acute toxicity evaluation, rats given HAE from Lampaya medicinalis leaves in a single dose level of $3000 \mathrm{mg} / \mathrm{kg}$ body weight, showed no mortality and none of them showed any symptom of toxicity. The behavioral pattern of animals was observed first $5 \mathrm{~h}$, $12 \mathrm{~h}$ and every day for 14 days after the administration, and the animals in both vehicle treated and extract treated groups were normal and did not display significant changes in general behavior. This visual observation showed no significant changes in behavior, skin effect, breathing, defecation, postural abnormalities, impairment in food intake and water consumption and yellowing or loss of hair, compared to negative control group (rats no treated). Neither mortality, nor tremors nor convulsions were noted after 14 days of treatment.

\section{Organ and body analysis}

The mean of rats body weight was measured on a daily basis for 14 consecutive days. No statistically significant differences were shown among group of rats treated compared with negative control group. The last day of treatment, animals were anesthetized and blood collected by cardiac puncture. The rats were sacrificed and liver, heart, kidney, lung and sexual organs were collected. There were no significant changes in relative organ weight between both control and treated groups. The relative liver weights were $2.70 \pm 0.03 \mathrm{~g} / 100 \mathrm{~g}$ of b.w. and $2.76 \pm 0.02 \mathrm{~g} / 100 \mathrm{~g}$ of b.w, for control and treated group, respectively. Values for kidneys were $0.37 \pm 0.02 \mathrm{~g} /$ $100 \mathrm{~g}$ of b.w. and $0.39 \pm 0.02 \mathrm{~g} / 100 \mathrm{~g}$ of b.w, for control and treated group, respectively. The results revealed that the essential organs as liver and kidney were not adversely affected throughout the treatment. Macroscopic analysis of target organs of treated animals did not show significant changes in color, volume and texture when compared with the control group.

\section{Biochemistry analysis}

After administering a dose of $3000 \mathrm{mg} / \mathrm{kg}$ b.w. of HAE from $L$. medicinalis, serum levels of alanine aminotransferase (ALT) were $57.40 \pm 2.79(\mathrm{IU} / \mathrm{L})$ and $11.00 \pm 1.41$ (IU/L) for the control group and the treated group, respectively. While the levels for aspartate aminotransferase (AST) were $208.60 \pm 4.35$ (IU/L) and $170.49 \pm 3.92$ (IU/L) for the control group and the treated group, respectively. In both cases the differences are not statistically significant.

\section{Histopathology of liver, heart, kidney, sexual organs and lung}

The microscopic structures of the organs described in Figure 1 shows unnoticeable differences between the control and test group. The microscopic examination revealed that liver, heart, kidney, sexual organs and lung from the extract treated rats did not show any alteration in cells structure or any unfavorable effects when viewed under the light microscope using multiple magnification power. The structure or coordination of cells of organs treated with extract of Lampaya medicinalis were similar compared with the control group. The cellular structures compared in each tissue were: central vein, sinusoids and 
hepatocytes in liver, cardiac muscle cell and connective tissue in heart, glomerulus, podocyte, Bowman's capsule, capillarie, proximal convoluted tubule and tubular lumen in kidney, spermatozoids, seminiferous tubule and interstitial Leydig cell in testis, oocyte, follicle, and follicular cells in ovarium tissue and bronchioli, alveoli, alveolar duct and blood vessel in lung.

\section{Rat paw edema assay}

The hydroalcoholic extract (HAE) of Lampaya medicinalis was very effective in causing inhibition of the paw volume in the carrageenan-induced paw edema in rat. The anti-inflammatory activity at test doses of 37.5, 75, 150 and $300 \mathrm{mg} / \mathrm{kg}$ body weight of HAE is presented in Table 1 with the average volume of carrageenan-induced rat paw edema. The percent protection of inflammation is presented in Table 2. The injection of carrageenan in paw created an inflammatory edema which increased gradually. HAE significantly inhibited the carrageenaninduced rat paw edema in dose - response relationship. The inhibitory values of edema at $3 \mathrm{~h}$ postcarrageenan were $31.04 \pm 0.75 \%, \quad 40.51 \pm 2.36 \%, \quad 48.97 \pm 1.14 \%$ and $56.87 \pm 0.41 \%$ for $37.5,75,150$, and $300 \mathrm{mg} / \mathrm{kg}$ of extract respectively. Indomethacin $(10 \mathrm{mg} / \mathrm{kg})$ gave a percentage inhibition of $49.44 \pm 1.44 \%$. HAE showed a significant effect even at the smallest dose $(37.5 \mathrm{mg} / \mathrm{kg})$, which inhibited paw edema by $30.16 \pm 0.91 \%$ at the $2^{\text {nd }}$ hour after carrageenan administration.

HAE at dose of $300 \mathrm{mg} / \mathrm{kg}$ exhibite an anti-inflammatory activity that became significant $1 \mathrm{~h}$ after the injection of carrageenan and was maintained all along the experiment. Maximum inhibition, $61.98 \pm 2.69 \%$, was noted at $300 \mathrm{mg} / \mathrm{kg}$ after $2 \mathrm{~h}$ of drug treatment carrageenan induced paw edema, whereas indomethacin produced $47.90 \pm 1.16 \%$ of inhibition. HAE (300 and $150 \mathrm{mg} / \mathrm{kg}$ ) induced an anti-inflammatory effect greater than (or comparable) with the effect of indomethacin from $2^{\text {nd }}$ to $4^{\text {th }}$ hours of the experiment.

\section{Phytochemical analysis}

Phytochemistry screening of the extracts revealed the presence of flavonoids, tannins, phenols and carbohydrates and reducing sugar.

\section{Discussion}

With the resurgence of the use of medicinal plants, scientific studies have become imperative to validate the folkloric use. In acute toxicity studies, a single dose of drug is given in large quantity to determine immediate toxic effect. These studies are commonly used to evaluate $\mathrm{LD}_{50}$, signs of changes in behavior, effects on biochemical parameter and histopathology assessment of the essential organs as liver and kidney [15].
Lampaya medicinalis is a plant used in altoandean traditional medicine at northern Chile for the treatment of various ailments. The acute oral toxicity of hydroalcoholic extract from leaves of Lampaya medicinalis was determined in the present study. 12 healthy rats from both sexes were employed to observe the toxicity effects of HAE. In this study the results showed that in a single dose there are no adverse effects of HAE of Lampaya medicinalis, indicating that the medium lethal dose $\left(\mathrm{LD}_{50}\right)$ is higher than $3000 \mathrm{mg} / \mathrm{kg}$ for rats. All animals treated with HAE survived beyond the 14 days observation period. The results revealed that the weights of liver and kidney were not adversely affected throughout the treatment. Macroscopic analysis of target organs of treated animals did not show significant changes in color, volume and texture when compared with the control group. Transaminases AST and ALT are well known enzymes used as biomarkers predicting possible toxicity. Increase in the level of AST and ALT in blood reflects the structural and functional dysfunction of hepatocellular membrane or cell rupture, and thereby indicate liver damage associated with tissue injury and reflection of hepatic toxicity. In the present study, AST and ALT levels were not affected by HAE, when is compared treated and controls animals. The lack of significant alterations in the levels of transaminases ALT and AST, good indicators of liver functions, suggests that acute ingestions of $L$. medicinals extract does not alter the hepatocytes of the rats, and, furthermore, the normal metabolism of the animals.

Histological examination is the golden standard for evaluating treatment related pathological changes in tissues and organs. Histological analysis of liver, heart, kidney, sexual organs and lung (Figure 1) showed an indistinguishable cellular architecture of the animals treated and the control group no treated, indicating that the HAE of Lampaya medicinalis did not adversely affect the morphology of organs of rats. The liver is the main target organ of acute toxicity where exposed to the foreign compounds which may or not to be hepatotoxic to the rats. In this study, the histological examination revealed that there was no potential toxicity or cellular lesions. Furthermore no necrosis or inflammation reaction was observed and the cell arrangement was similar to the organs of the control rats and treated.

Therefore, it can be suggested that HAE did not interact with the target cells or change the biological systems of the animals.

The most commonly used test to study new antiinflammatory agents evaluates the ability of the chemical material to reduce local edema induced in the rat paw by injection of an irritant agent [16]. Irritant agents commonly used are: histamine, dextran, serotonin, carrageenan [17]. The development of edema in the paw of the rat after injection of carrageenan has been accepted as a 
useful tool for investigating systemic anti-inflammatory agent [18]. The inflammation model of a carrageenan induced edema is usually used to assess the activity of natural products in resisting the pathological changes associated with acute inflammation $[19,20]$. Inflammation induced by carreegenan is acute, non immune, wellresearched, and highly reproducible. Cardinal signs of inflammation - edema, hyperalgesia, and erythema - developed immediately after subcutaneous injections a result of the action of proinflammatory agents and reactive oxygen and nitrogen species [21].

The inflammatory response is usually quantified by increase in paw size (edema) which is maximal around $5 \mathrm{~h}$ postcarregenan injection. The results obtained from the carrageenan-induced paw edema shows that paw edema was markedly inhibited by the oral administration of the hydroalcoholic extract of Lampaya medicinalis (HAE) in dose - response relationship. The effect observed, which was time-dependent, lasted for at least $4 \mathrm{~h}$ with the two highest doses. The inhibitory values of edema at indicating that the extract is orally active at doses ranging from $37.5-300 \mathrm{mg} / \mathrm{kg}$ and can inhibit a acute inflammatory process [22].

\section{Conclusions}

Hydroalcoholic extract of Lampaya medicinalis Phil leaf up to the dose level $3000 \mathrm{mg} / \mathrm{kg}$ body weight did not produce any toxic effects or deaths; the extract was well tolerated by the rats. It did not alter body weight, feed and water consumption. The organ weight, biochemical and hematological analysis did not show changes in any of the parameters examined in animals of both sexes. The acute oral administration of the hydroalcoholic extract of Lampaya medicinalis Phil leaf was safe and not toxic in a single dose.

Finally, the results of present study shows that L. medicinalis has anti-inflammatory activity. Therefore, the practice of drinking the infusion of the plant for treatment of rheumatism, arthritis and body joints pain by traditional medical practitioner is not totally out of place. There is a need for further studies in order to isolate the anti-inflammatory ingredients in the plant and determine their mechanism of action.

\section{Methods}

Plant material

Leaves and aerial parts of Lampaya medicinalis Phil were collected at Socaire in Northern Chile $\left(23^{\circ} 36^{\prime} 40\right.$ s S; $67^{\circ}$ 50 '33 s W, $3230 \mathrm{~m}$ above sea level). The material was identified by Professor Roberto Rodriguez, Facultad de Ciencias Biológicas y de Recursos Naturales de la Universidad de Concepción and voucher specimens are kept at the Herbarium of Universidad de Concepción, Chile.

\section{Preparation of the hydroalcoholic extract (HAE)}

The air-dried leaves of Lampaya medicinalis Phil (1.2 kg) were chopped and exhaustively extracted with EtOH: $\mathrm{H}_{2} \mathrm{O}$ $(1: 1,10 \mathrm{~L})$ during one week at room temperature. The EtOH: $\mathrm{H}_{2} \mathrm{O}$ extract was then filtered, evaporated under reduced pressure and freeze - dried to obtain a viscous mass of dark green extract (HAE). The yield of the lyophilized aqueous - ethanol solution was $12.5 \%(\mathrm{w} / \mathrm{w})$. The dried extract was sealed in a bottle and stored in the refrigerator at $4^{\circ} \mathrm{C}$ until further use. Just prior to the biological testing the extract was dissolved in saline to prepare a stock solution of $200 \mathrm{mg} / \mathrm{mL}$.

\section{Target animals}

Sprague-Dawley rats of both sex weighing 180-220 g were obtained from animal house of Facultad de Ciencias de la Salud de la Universidad de Antofagasta.

The animals were maintained on a standard pellet diet with free access to water and housed under controlled room temperature at $22 \pm 2^{\circ} \mathrm{C}$ with lighting from 8:00 to 20:00.

The animals were used taking into account international principles and local regulation concerning the care and use of laboratory animals. All experimental protocols were approved by the Comité de Etica de la Universidad de Antofagasta.

\section{Acute toxicity study}

The acute oral toxicity study was performed as per OECD-423 guidelines [12], 12 animals in 2 groups of 6 rats/group (3 males and 3 females) were used for the study. Drinking water and food were provided ad libitum, except for the short fasting period where the water was in free access but no food was provided $12 \mathrm{~h}$ before treatment. Stock solution of HAE, $200 \mathrm{mg} / \mathrm{mL}$, was made in saline. Following the fasting period, body weight of each animals were determined and the dose was calculated in reference to the body weight as volume of the stock solution. HAE at dose of $3000 \mathrm{mg} / \mathrm{kg}$ body weight were administrated by gastric gavage using a suitable intubation cannula in the treatment group. Other 3 males and 3 females were allotted saline and were regarded as control group. After the substance has been administered, food may be withheld for a further 2-3 hours.

All the animals were observed after the administration of the HAE. Thereafter, observation were made at every hour for $5 \mathrm{~h}$, then at $12 \mathrm{~h}$ and every day for 14 days. All observation were systematically recorded, with individual records being maintained for each animal. The observation of the cage includes the evaluation the skin and the eyes; the breathing effects; the effects of the autonomous system as salivation, diarrhea, micturition; the central nervous effects, as tremors and convulsion. At the end of the acute toxicity study, all animals were fasted $12 \mathrm{~h}$ 


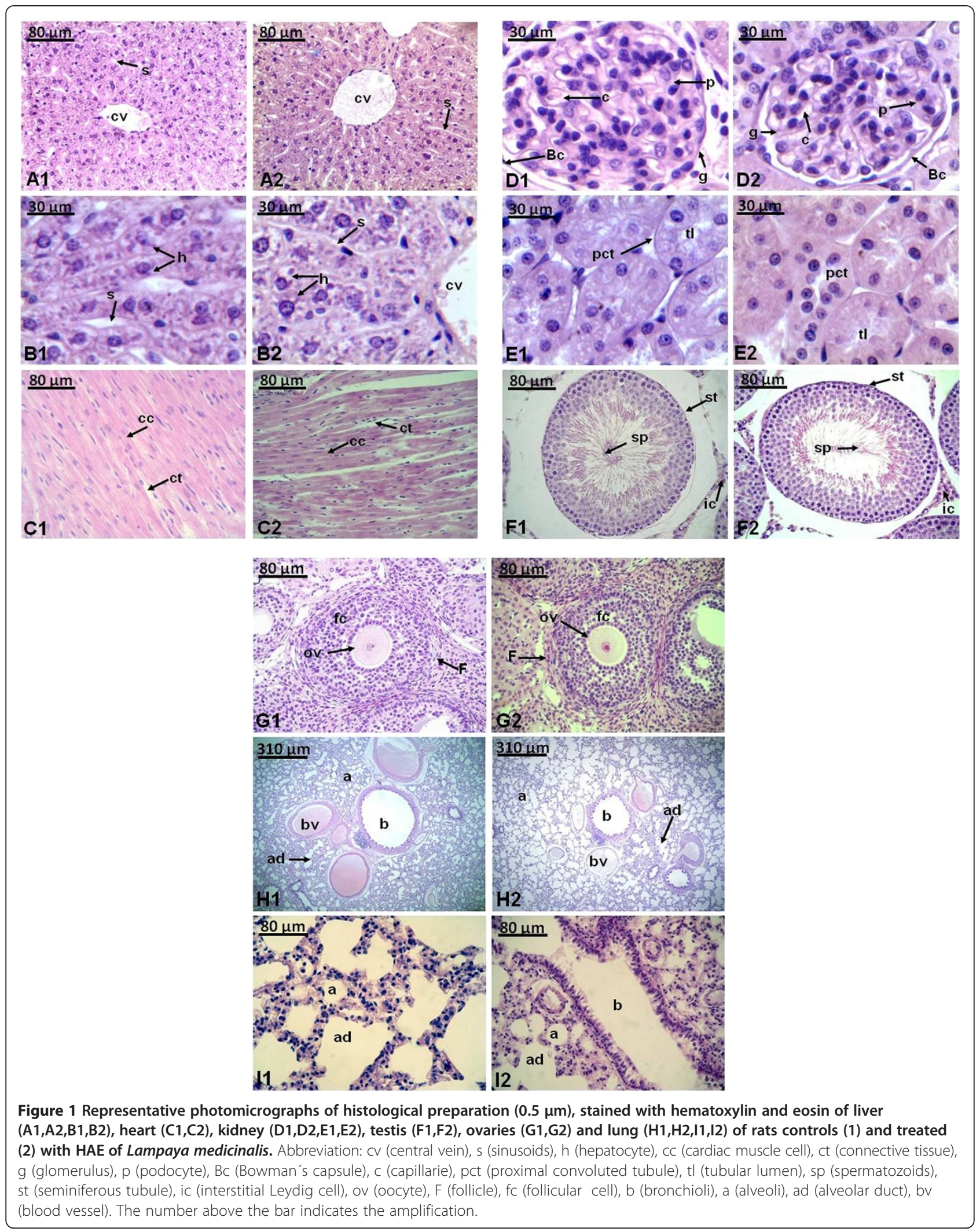


Table 1 Volume of paw edema

\begin{tabular}{|c|c|c|c|c|c|c|}
\hline \multirow{3}{*}{$\begin{array}{l}\text { Time } \\
\text { (hours) }\end{array}$} & \multicolumn{6}{|c|}{ Volume of paw edema $(\mathrm{mL})$} \\
\hline & \multirow[t]{2}{*}{ Control } & \multicolumn{4}{|c|}{ HAE } & \multirow{2}{*}{$\begin{array}{l}\text { Indomethacin } \\
(10 \mathrm{mg} / \mathrm{kg})\end{array}$} \\
\hline & & $300 \mathrm{mg} / \mathrm{kg}$ & $150 \mathrm{mg} / \mathrm{kg}$ & $75 \mathrm{mg} / \mathrm{kg}$ & $37.5 \mathrm{mg} / \mathrm{kg}$ & \\
\hline 1 & $1.86 \pm 0.32$ & $0.96 \pm 0.22$ & $1.39 \pm 0.35$ & $1.53 \pm 0.29$ & $1.58 \pm 0.16$ & $0.91 \pm 0.02$ \\
\hline 2 & $2.63 \pm 0.10$ & $1.00 \pm 0.27$ & $1.43 \pm 0.17$ & $1.39 \pm 0.18$ & $1.84 \pm 0.58$ & $1.37 \pm 0.11$ \\
\hline 3 & $2.69 \pm 0.23$ & $1.16 \pm 0.09$ & $1.37 \pm 0.22$ & $1.60 \pm 0.15$ & $1.86 \pm 0.36$ & $1.36 \pm 0.44$ \\
\hline 4 & $1.82 \pm 0.21$ & $0.81 \pm 0.26$ & $1.12 \pm 0.45$ & $1.46 \pm 0.71$ & $1.53 \pm 0.78$ & $1,19 \pm 0.20$ \\
\hline 5 & $1.21 \pm 0.17$ & $0.89 \pm 0.18$ & $0.94 \pm 0.19$ & $1.04 \pm 0.97$ & $1.07 \pm 0.82$ & $0.77 \pm 0.17$ \\
\hline
\end{tabular}

Results are shown as mean edema volume \pm SEM $(n=6)$ compared with control group. Statistical significance according to Student's $t$ test. $P<0.05$.

and then, under a soft anesthesia were sacrificed and blood samples collected by heart puncture. The blood samples were centrifuged to $3000 \mathrm{rpm}$ during $15 \mathrm{~min}$. Serum samples were analyzed immediately for the determination of aspartate aminotransferase (AST) and alanine aminotransferase (ALT) by standard enzymatic methods using commercially available kit from SigmaAldrich.

Heart, kidneys, liver, lung, testes and ovaries of all animals were dried with filter paper, weighed using a analytic balance, and the relative weights expressed as $\mathrm{g} / 100 \mathrm{~g}$ of body weights. The morphology was macroscopically observed for signs of toxicity. Samples of organs isolated from each individual were dehydrated by serial ethanol solution and enclosed with paraffin wax. Micrometer sections $(5 \mu \mathrm{m})$ cut with microtome were stained with hematoxylin and eosin and were examined under a light microscope, photomicrographs of the samples were recorded.

\section{Rat paw edema assay}

The carrageenan-induced hind paw edema test was perfomed according to $[18,23]$. Sprague-Dawley rats of 180-220 g body weight divided into 6 groups with each group containing 6 rats. The control group and the reference group received normal saline $(0.9 \% \mathrm{NaCl}, 2 \mathrm{~mL} / \mathrm{kg})$ and indomethacin $(10 \mathrm{mg} / \mathrm{kg})$, respectively. While the test groups were treated with $37.5,75,150$ and $300 \mathrm{mg} / \mathrm{kg}$ body weight of extract, respectively. Saline, extract and indomethacin were all administered orally. Carrageenaninduced inflammation was produced by injection of $0.1 \mathrm{~mL}$ of a freshly prepared $1 \% \lambda$ carrageenan suspended in sterile physiological saline into the right hind foot of each rat under the subplantar aponeurosis. The control, reference and the test groups were treated orally with saline, indomethacin and the extract $1 \mathrm{~h}$ before carrageenan injection. Paw volume was measured by a digital water plethysmometer (Ugo Basile, model 7140, Italy), before the treatment $\left(V_{0}\right)$ and 1,3,4,5 $\mathrm{h}$ after carrageenan injection $\left(V_{t}\right)$. The increase in volume was taken as the volume of edema and was determined for each rat $\left(V_{0}\right)$. The percent of edema inhibition in treated animals versus control no treated was calculated by the following equation $[24,25]$.

$$
\text { Anti-inflammatory activity }(\%)=(1-\mathrm{D} / \mathrm{C}) \times 100 \text {, }
$$

where D represents the edema volume after extract was administered to the rat and $\mathrm{C}$ represents the edema volume in control group.

\section{Phytochemical screening}

Hydroalcoholic extract freeze-dried of Lampaya medicinalis was phytochemical screened in order to detected the presence (or absence) of alkaloids (Draggendorf and Meyer reagent), carbohydrates and reducing sugar (Molisch and Fehling reagent), flavonoids (Shinoda test), tannins and phenols (iron chloride) and terpenoids (LiebermanBurchard test) [14].

Table 2 Percentage of inhibition inflammation

\begin{tabular}{|c|c|c|c|c|c|}
\hline \multirow{3}{*}{$\begin{array}{l}\text { Time } \\
\text { (hours) }\end{array}$} & \multicolumn{5}{|c|}{$\%$ inhibition of inflammation } \\
\hline & \multicolumn{4}{|c|}{ HAE } & \multirow{2}{*}{$\begin{array}{r}\text { Indomethaci } \\
(10 \mathrm{mg} / \mathrm{kg})\end{array}$} \\
\hline & (300 mg/kg) & $(150 \mathrm{mg} / \mathrm{kg})$ & (75 mg/kg) & $(37.5 \mathrm{mg} / \mathrm{kg})$ & \\
\hline 1 & $48.38 \pm 0.13$ & $25.05 \pm 1.13$ & $17.63 \pm 1.12$ & $15.04 \pm 0.53$ & $51.07 \pm 0.30$ \\
\hline 2 & $61.98 \pm 2.69$ & $45.49 \pm 0.75$ & $47.13 \pm 1.06^{*}$ & $30.16 \pm 0.91$ & $47.90 \pm 1.16$ \\
\hline 3 & $56.87 \pm 0.41$ & $48.97 \pm 1.14^{*}$ & $40.51 \pm 2.36$ & $31.04 \pm 0.75$ & $49.44 \pm 1.44$ \\
\hline 4 & $55.49 \pm 1.22$ & $38.46 \pm 1.20$ & $19.78 \pm 0.79$ & $15.93 \pm 0.22$ & $34.61 \pm 0.81$ \\
\hline 5 & $26.45 \pm 1.07$ & $22.31 \pm 0.75$ & $14.05 \pm 1.02$ & $11.57 \pm 0.61$ & $36.36 \pm 0.42$ \\
\hline
\end{tabular}

Results inhibition percentage \pm SEM $(n=6)$ when compared with control group (Indomethacin). Statistical significance according to Student's $t$ test $(P<0.05)$.

*Represent values not significant when compared with control. 


\section{Statistical analysis}

Results were expressed as the mean \pm SEM. Treated groups were compared with the controls for statistical significant differences $(\mathrm{p}<0.05)$ using paired Student's $t$-test.

\section{Competing interests}

The authors declare that they have no competing interests.

\section{Authors' contributions}

GM was responsible for conducting the experiments, data analysis and interpretation and preparing the manuscript.AP carried out the collection of plants extraction process and anti-inflammatory activities in carrageenan-induced rat paw edema. AO was responsible for the histological analysis and helped to revision of the manuscript. JB was responsible for the biochemical and hematological analysis. All authors have read and approved the final manuscript.

\section{Acknowledgements}

This work was funded by the "Fondo de Innovacion para la Competitividad Regional", FIC-R, Antofagasta and "Fundación para la Innovación Agraria" FIA grant N EST 2010-0157.

\section{Author details}

'Departamento de Química. Facultad de Ciencias Básicas, Universidad de Antofagasta, Antofagasta, Chile. 'Laboratorio de Química Biológica, Instituto Antofagasta (IA), Universidad de Antofagasta, Antofagasta, Chile ${ }^{3}$ Departamento de Acuicultura, Facultad de Recursos del Mar, Universidad de Antofagasta, Antofagasta, Chile. ${ }^{4}$ Departamento Biomédico, Facultad de Ciencias de la Salud, Universidad de Antofagasta, Antofagasta, Chile.

Received: 27 July 2013 Accepted: 17 December 2013

Published: 26 March 2014

\section{References}

1. Atsamo AD, Nguelefack TB, Datté JY, Kamanyi A: Acute and subchronic oral toxicity assessment of the aqueous extract from the stem bark of Erythrina senegalensis DC (Fabaceae) in rodents. J Ethnopharmacol 2011, 134:697-702.

2. Harizal SN, Mansor SM, Hasnan J, Tharakan JKJ, Sbdullah J: Acute toxicity study of the standardized methanolic extract of Mitragyna speciosa Korth in Rodent. J Ethnopharmacol 2010, 131:404-409.

3. Saha P, Mazumder UK, Haldar PK: Acute and Subchronic Toxicity of $C$. maxima Aerial Parts. Int J Res Pharm Sci 2011, 2:634-639.

4. Formagio ASN, Kassuya CAL, Formagio Neto F, Volobuff CRF, Iriguchi EKK, Viera M, Do C, Foglio MA: The flavonoid content and antiproliferative, hyploglycaemic, anti-inflammatory and free radical scavenging activities of Annona dioica St. Hill. BMC Complementary and Alternative Medicine 2013, 13(14):2-8

5. Adedapo AA, Sofidiya MO, Maphosa V, Moyo B, Masika PJ, Afolayan AJ: Anti-inflammatory and analgesic activities of aqueous extract of Cussonia paniculata stem Bark. Red Nat Prod 2008, 2:46-53.

6. Kim HP, Son KH, Chang HW, Kang SS: Anti-inflammatory Plant Flavonoids and Cellular Action Mechanism. J Pharmacol Sci 2004, 96:229-245.

7. Mellado V, Medina E, San Martin C: Herbolaria Medica de Chile Ministerio de Salud Santiago de Chile; 1997:168-169.

8. Castro V: Botánica y Pueblos Originarios. Actas $2^{\circ}$ Congreso de Plantas Medicinales. Centro El Canelo de Nos. San Bernardo, Chile; 1995:49.

9. Monterrey N: Hierbas medicinales andinas de la $2^{a}$ Región. Ministerio de Educación. Santiago de Chile; 1994:33-35.

10. Gomez D, Ahumada J, Necul E: Medicina tradicional atacameña. Ministerio de Educación. Santiago de Chile; 1997:61-74.

11. Alvarez ME, Rotelli AE, Pelzer LE, Saad JR, Giordano O: Phytochemical study and anti-inflammatory properties of Lampaya hieronymi. ex Moldenke. II Farmaco 2000, 55:502-505.

12. OECD: OECD/OCDE Guidelines for acute toxicity of chemicals. Paris, France: Organization for Economic Co-operation and Development; 2001: $N^{\circ} 423$

13. OECD: OECD/OCDE Guidelines for the testing of chemicals. Paris, France: Organization for Economic Co-operation and Development; 2008: $\mathrm{N}^{\circ} 425$.
14. Mikail HG: Phytochemical screening, elemental analysis and acute toxicity of aqueous extract of Allium sativum L. bulbs in experimental rabbits. J Med Plant Res 2010, 4:322-326.

15. Chanda S, Dave R, Kaneria M, Sukla V: Acute oral toxicity of Polyalthia longifolia var. pendula leaf extract in Wistar albino rats. Pharm Biol 2012, 50:1408-1415

16. Miceli N, Taviano MF, Giuffrida D, Trovato A, Tzakou O, Galati EM: Anti-inflammatory activity of extract and fractions from Nepeta sibthorpii Bentham. J Ethnopharmacol 2005, 97:261-266.

17. Gupta M, Mazumder UK, Gomathi P, Thamil Selvan V: Anti-inflammatory evaluation of leaves of Plumeria acuminate. BMC Complement Altern Med 2006, 6:36.

18. Morris CJ: Carrageenan - induced Paw Edema in the Rat and Mouse. In Methods in Molecular Biology, vol. 225; Inflammation Protocols. Chapter 13th edition. Edited by Winyard PG, Willoughby DA. Totowa, NJ: Humana Press Inc; 2003:115-121.

19. Sawadogo WR, Boly R, Lompo M, Some N, Lamien CE, Guissou IP, Nacoulma OG Anti-inflammatory, Analgesic ad Antipyretic Activities of Dicliptera verticillata. Intl J Pharmacol 2006, 2:435-438.

20. Wang BS, Huang GJ, Lu YH, Chang LW: Anti-inflammatory effects of an aqueous extract of Welsh onion green leaves in mice. Food Chem 2013, 138:751-756.

21. Pan MH, Lai CS, Ho CT: Anti-inflammatory activity of natural dietary flavonoids. Food Funct 2010, 1:15-31.

22. Owoyele VB, Oloriegbe YY, Balogun EA, Soladoye AO: Analgesic and anti-inflammatory properties of Nelsonia canescens leaf extract. J Ethnopharmacol 2005, 99:153-156.

23. Meckes $M$, David-Rivera AD, Nava-Aguilar $V$, Jimenez A: Activity of some Mexican medicinal plant extracts on carrageenan-induced rat paw edema. Phytomedicine 2004, 11:446-451.

24. Kumar V, Bhat ZA, Kumar D, Khan NA, Chashoo IA: Evolution of anti-inflammatory potential of leaf extracts of Skimmia anquetilia. Asian Pac J Trop Biomed 2012, 2:627-630.

25. Adedapo AA, Sofidiya MO, Afolayan AJ: Anti-inflammatory and analgesic activities of the aqueous extracts of Margaritaria discoidea (Euphorbiaceae) stem bark in experimental animal models. Int/ J Trop Biol 2009, 57(4):1193-1200.

doi:10.1186/0717-6287-47-6

Cite this article as: Morales et al:: Acute oral toxicity and anti-inflammatory activity of hydroalcoholic extract from Lampaya medicinalis Phil in rats. Biological Research 2014 47:6.

\section{Submit your next manuscript to BioMed Central and take full advantage of:}

- Convenient online submission

- Thorough peer review

- No space constraints or color figure charges

- Immediate publication on acceptance

- Inclusion in PubMed, CAS, Scopus and Google Scholar

- Research which is freely available for redistribution

\section{Submit your manuscript at}

